http://jmscr.igmpublication.org/home/ ISSN (e)-2347-176x ISSN (p) 2455-0450 crossref DOI: https://dx.doi.org/10.18535/jmscr/v8i9.11

\author{
Journal Of Medical Science And Clinical Research \\ IGM Publication \\ An Official Publication of IGM Publication
}

Original Article

\title{
Clinico-Epidemiology Profile of Molar Pregnancy in Tertiary Care Centre: A Retrospective Review of Medical Records
}

Authors

Dr Vinod ${ }^{1} *$, Dr Kalpana Mehta ${ }^{2}$, Dr Vimla Choudhary ${ }^{3}$, Dr Ramniwas ${ }^{4}$, Dr Anusha

${ }^{1} 3^{\text {rd }}$ Year Resident, ${ }^{2}$ Senior Professor \& Unit Head, ${ }^{3}$ Assistant Professor, ${ }^{4,5} 2^{\text {nd }}$ Year Resident

Department of Obstetrics and Gynaecology, MDM Hospital, Dr. S. N. Medical College, Jodhpur, Rajasthan

*Corresponding Author

Dr Vinod

Department of Obstetrics and Gynaecology, MDM Hospital, Dr. S. N. Medical College, Jodhpur, Rajasthan

\begin{abstract}
Background: Gestational trophoblastic disease (GTD) includes a series of disorders that are characterized by an abnormal proliferation of trophoblastic tissue with varying tendency to spontaneous remission, local invasion and metastasis. The incidence of GTD varies greatly in different parts of the world. Hydatidiform mole presents with amenorrhea, painless vaginal bleeding and spontaneous passage of grape-like vesicles, high serum and urinary $\beta$ human chorionic gonadotrophin ( $\beta H C G)$ levels.

Objective: To study epidemiology \& clinical profile of Gestational Trophoblastic Disease and to evaluate its management and outcome.

Material and Methods: A retrospective study was conducted over a period of five years in MDM Hospital, Jodhpur. A total of 39301 pregnancies were recorded during the period of five years. The demographic profile, clinical presentation, management and complications were studied.

Results: There were 60 patients of GTD with an incidence of 1.52 per 1,000 pregnancies. Among these 60 cases, 45 (75\%) cases had complete H mole. Most of the patients (63.3\%) were in age group of 21-30 years and majority in nulliparous women (38.3\%). Majority of the molar pregnancy cases $83.3 \%$ cases have been detected in the second trimester. The most common clinical presentation was bleeding per vaginum constituting $58.3 \%$ of cases. Majority (85\%) of the patients were treated by suction and evacuation.

Conclusion: Gestational Trophoblastic Disease requires early diagnosis, treatment and strict monitoring to be $100 \%$ curable. Routine check-up helps to timely management of the GTDs thereby preventing their progression to GTN.
\end{abstract}

Keywords: Gestational Trophoblastic Disease, Hydatidiform Mole, Molar Pregnancy, Neoplasia, Serum beta $H C G$.

\section{Introduction}

Gestational trophoblastic disease (GTD) includes a series of disorders that are characterized by an abnormal proliferation of trophoblastic tissue with varying tendency to spontaneous remission, local invasion and metastasis ${ }^{1}$. It encompasses several distinct clinical entities, from benign complete and partial hydatidi form moles to malignant invasive moles, choriocarcinoma, placental site trophoblastic tumour (PSTT), and epithelioid 
trophoblastic tumor; malignant forms of GTD are grouped together under the term gestational trophoblastic neoplasia $(\mathrm{GTN})^{2}$. Hydatidiform mole is the most common $\mathrm{GTD}^{3,4}$.

The incidence of GTD varies greatly in different parts of the world, with 0.4 per 1000 birth in United States of America to 12.5 per 1000 births in Taiwan ${ }^{5}$. In Nepal, hospitals in Kathmandu valley have recorded its incidence as 5.1, 2.9, 2.8, and 4.1 per 1000 live births ${ }^{6}$. These 10-20fold variations in the incidence of molar pregnancy might be overestimated by reporting biases, such as population-based and hospital-based data ${ }^{7}$. In addition, incidence rates may be based on the total number of pregnancies, deliveries or live births. Furthermore, under registration of GTD might occur $^{1}$. The incidence of GTD in India was found to be one per 967 pregnancies in an epidemiological study on GTD in a North Indian population ${ }^{8}$. Incidence of molar pregnancy in India is 19.1 per 10,000 deliveries (Pai) according to hospital based studies 9 .

Clinically hydatidiform mole presents with amenorrhoea, painless vaginal bleeding and spontaneous passage of grape-like vesicles, high serum and urinary $\beta$ human chorionic gonadotrophin ( $\beta$ HCG) levels. There may also be hyperemesis gravidarum, doughy uterus, inappropriate uterine size, bilateral theca lutein cyst and rarely, features of thyrotoxicosis and preeclampsia in the first half of pregnancy ${ }^{10-12}$. Hydatidiform mole is a relatively common gynecological problem which could present like spontaneous abortion, one of the most common gynecological emergencies. Ultrasonography is a simple non-invasive examination which can correctly identify the placental molar transformations in-utero. Currently with widespread use of first trimester ultrasonography a significant proportion of patients with molar pregnancy are asymptomatic at the time of diagnosis. Careful and reliable human chorionic gonadotropin monitoring is essential for the early detection of post molar persistent gestational trophoblastictumor. Therefore we conducted a study to determine the epidemiology \& clinical profile of Gestational Trophoblastic Disease and to evaluate its management and outcome.

\section{Material and Methods}

Study Population: A retrospective study was conducted in conducted in the Department of Obstetrics and Gynecology, MDM Hospital under Dr S N Medical College, Jodhpur, Rajasthan over a period of five years from January 2015 to December 2019. There were 39301 pregnancies were enrolled from gynaecological outpatient clinic of MDM Hospital. The study was approved by the Institute Ethics Committee.

Methodology: A total of 39301 pregnancies were recorded during the period of five years and 60 patients were diagnosed as having GTD. All women under study were subjected to a detailed history as per the preset proforma including age, address, chief presenting complaint, gravidity, gestational age, outcome of previous pregnancies, menstrual history were noted for each case.

The clinical examination included nutritional status, height, weight, BMI calculation, pallor, oedema, PR, BP, thyroid swelling. Size of the uterus per abdomen was noted to check if it corresponded to the weeks of gestation. A difference of at least 4 weeks between uterine size and gestational age was considered significant. Per speculum and per vaginal examination was done. CVS and RS examined.

Blood samples collected for investigations which included $\mathrm{Hb} \%$, blood grouping and $\mathrm{Rh}$ typing, thyroid function test, serum beta-hCG. Cross matching samples were drawn if blood transfusion required. Urine samples collected for albumin, sugar and microscopy. The patients were subjected to USG if not previously done. As a primary mode of management suction and evacuation done for all patients followed by gentle curettage was done. The samples obtained sent for histopathological examination. The serum beta hCG was repeated $48 \mathrm{hrs}$ after evacuation. Post evacuation USG was done if the patient complained of excessive or irregular bleeding per 
vaginum. Repeat evacuation was done if there was evidence of retained molar tissue on post evacuation USG.

Then the patients were counselled regarding the need for follow up and use of contraception for the entire period of follow up. Follow up was done with weekly beta hCG until normal for 3 consecutive weeks followed by monthly determination until the levels were normal for 6 consecutive months. The normal level of beta hCG was taken as less than $10 \mathrm{mIU} / \mathrm{L} .{ }^{72}$ At every follow up visit history regarding irregular vaginal bleeding, pain abdomen, headache, cough, hemoptysis, fever was taken and clinical examination which included CVS, RS, per abdomen, per speculum, per vaginal examination done to look for signs of GTN. The time to achieve the first normal beta hCG after evacuation was noted.

GTN was diagnosed during follow up either on the basis of a rise in serum beta hCG levels or histopathology or with evidence of metastasis. Women diagnosed with persistent trophoblastic disease or GTN were scored according to modified WHO scoring system [Table- 1] ${ }^{13}$

\section{Results}

A total of 39301 pregnancies were recorded during the period of four years and 60 patients were diagnosed as having Gestational trophoblastic disease. This gives an incidence of 1.52 per 1,000 pregnancies. Among these 60 cases, 45 (75\%)cases had complete H. mole, 12 $(20 \%)$ cases had partial H. mole and $3(5 \%)$ cases had GTN at the time of presentation. During follow up 2(4\%) more patients of complete mole turned into GTN. The incidence of GTN was found to be 0.07 per 1000 pregnancies ( 4 out of 28,301 pregnancies) (Table-2).

Most of the patients (63.3\%) were in age group of 21-30 years. In this study $\mathrm{H}$. mole was more common in nulliparous women $(38.3 \%)$ while the least was $6.7 \%$ in women with parity four and above. Majority of the molar pregnancy cases $83.3 \%$ cases have been detected in the second trimester while $16.6 \%$ cases have been detected in the second month of gestation. No cases were detected after 20 weeks gestation. (Table 2)

Majority $86.6 \%$ of the cases had anaemia and required blood transfusions. Excessive uterine size was observed among $78.4 \%$ of the cases while $70 \%$ of the cases had beta HCG levels were greater than $100000 \mathrm{mIU} / \mathrm{ml}$. These features indicated marked trophoblastic proliferation, considered as high risk mole. Hyperthyroidism was seen in $8.3 \%$ of cases. Theca luetin cysts were observed in $10 \%$ of cases. (Table 3 )

The most common clinical presentation was bleeding per vaginum constituting $58.3 \%$ of cases while the least common clinical presentation was Incidental US finding after a routine obstetric scan was $5 \%$ of cases.

Majority $(85 \%)$ of the patients were treated by suction and evacuation. Hysterotomy was done in a patient who was diagnosed on USG with single live intrauterine fetus of 21 weeks with bulky cystic placenta completely covering the internal os (partial mole with placenta praevia). Three (5\%) patients underwent subsequent total abdominal hysterectomy when they were found to have GTN in their follow up (including two post evacuation patients referred from peripheral centers). Secondary curettage was done in one patient in their first follow up visits when they complained of excessive bleeding per vaginum \& their USG showed echogenic material in endometrial canal and retained products of conception was found in histopathology. Majority (90\%) of patients had spontaneous remission defined as three consecutive $\beta$-hCG value undetectable. $8.33 \%$ patients progressed to GTN in present study. One patient lost to follow up (1.6\%). Among the 05 cases of GTN, 3 developed invasive mole and 1 developed choriocarcinoma while one of them showed rising titres without any other specific sign \& symptom, so was categorized persistent trophoblastic disease and was referred to oncology department for chemotherapy. Because of small number of patients in present study there is higher percentage of GTN [Table-5]. 
Table 1 Modified WHO prognostic scoring system for GTN as adopted by FIGO

\begin{tabular}{|l|c|c|c|c|c|}
\hline SI No. & Risk Factor & \multicolumn{4}{|c|}{ Risk Score } \\
\cline { 3 - 6 } & Age (years) & 0 & 1 & 2 & 4 \\
\hline 1 & Antecedent pregnancy & Mole & Abortion & Term & - \\
\hline 2 & $\begin{array}{c}\text { Interval from antecedent } \\
\text { pregnancy to chemotherapy } \\
\text { (months) }\end{array}$ & $<4$ & $4-6$ & $7-12$ & $>12$ \\
\hline 3 & hCG concentration (mIU/ml) & $<10^{3}$ & $10^{3}-<10^{4}$ & $10^{4}-10^{5}$ & $>10^{5}$ \\
\hline 4 & Number of metastasis & 0 & $1-4$ & $4-8$ & $>8$ \\
\hline 5 & $\begin{array}{c}\text { Site of metastasis } \\
\text { Linger }\end{array}$ & Lung & $\begin{array}{c}\text { Spleen, } \\
\text { Kidney }\end{array}$ & $\begin{array}{c}\text { Gastrointestinal } \\
\text { Tract }\end{array}$ & Brain, Liver \\
\hline 7 & $\begin{array}{c}\text { Largest tumour mass } \\
\text { diameter(cm) }\end{array}$ & - & $3-5$ & $>5$ & - \\
\hline 8 & $\begin{array}{c}\text { Previous failed chemotherapy } \\
\text { drugs }\end{array}$ & - & - & Monotherapy & $\begin{array}{c}\text { Combined } \\
\text { therapy }\end{array}$ \\
\hline
\end{tabular}

Table 2 Demographic profile, Risk Factor and Clinical presentation of Gestational Trophoblastic Disease

\begin{tabular}{|c|c|c|c|c|}
\hline SI No. & Demographic variable & Range & Number & Percentage \\
\hline & GTD & $\begin{array}{l}\text { Complete and Partial H. } \\
\text { mole; and GTN }\end{array}$ & 60 & $\begin{array}{l}1.52 / 1000 \\
\text { Pregnancies }\end{array}$ \\
\hline \multirow{4}{*}{1} & \multirow{4}{*}{ Age } & $<20$ years & 08 & 13.3 \\
\hline & & $21-30$ years & 38 & 63.3 \\
\hline & & $31-40$ years & 10 & 16.6 \\
\hline & & $>40$ years & 04 & 6.7 \\
\hline \multirow[b]{2}{*}{2} & \multirow[b]{2}{*}{ Gestational Period } & $<8$ weeks & 10 & 16.6 \\
\hline & & $8-20$ weeks & 50 & 83.4 \\
\hline \multirow{5}{*}{3} & \multirow{5}{*}{ Parity } & Nullipara & 23 & 38.3 \\
\hline & & Para 1 & 19 & 31.6 \\
\hline & & Para 2 & 09 & 15 \\
\hline & & Para 3 & 05 & 8.3 \\
\hline & & Para 4 and above & 04 & 6.7 \\
\hline
\end{tabular}

Table 3 Associated features with Gestational Trophoblastic Disease

\begin{tabular}{|l|c|c|c|}
\hline SI No. & Risk factor & Number of cases & Percentage \\
\hline 1 & Beta HCG $>100000 \mathrm{mIU} / \mathrm{ml}$ & 42 & 70 \\
\hline 2 & Neoplasia & 10 & 16.7 \\
\hline 3 & Hyperthyroidism & 05 & 8.3 \\
\hline 4 & Anaemia & 52 & 86.6 \\
\hline 5 & Excessive uterine size & 47 & 78.4 \\
\hline 6 & Recurrent mole & 02 & 3.3 \\
\hline 7 & Theca leutin cyst & 06 & 10 \\
\hline
\end{tabular}

Table 4 Clinical presentation of cases

\begin{tabular}{|l|c|c|c|}
\hline SI No. & Presentation & Number of cases & Percentage \\
\hline 1 & Bleeding per vaginum & 35 & 58.3 \\
\hline 2 & Amenorrhoea & 12 & 20 \\
\hline 3 & Pain abdomen & 10 & 16.7 \\
\hline 4 & US finding & 03 & 5 \\
\hline
\end{tabular}


Table 5 Diagnosis, Management and Outcome of Molar Pregnancy

\begin{tabular}{|c|c|c|c|c|}
\hline Sl. No & & & No. of cases & Percentage \\
\hline \multirow[b]{2}{*}{1.} & \multirow[b]{2}{*}{ Primary Diagnostic Modality } & $\begin{array}{l}\text { Radiological finding (dating scan for early } \\
\text { pregnancy) }+\beta \text { hCG level thereafter }\end{array}$ & 57 & 95 \\
\hline & & $\begin{array}{c}\text { Histopathology(Clinically } \\
\& \text { radiologically diagnosed as Missed } \\
\text { abortion) }\end{array}$ & 03 & 5 \\
\hline \multirow{4}{*}{2} & \multirow{4}{*}{$\begin{array}{c}\text { Preevacuation } \beta \text { hCG level } \\
(\mathrm{mIU} / \mathrm{ml})\end{array}$} & $<10^{3}$ & 05 & 8.33 \\
\hline & & $10^{3}-10^{4}$ & 21 & 35 \\
\hline & & $10^{4}-10^{5}$ & 10 & 16.66 \\
\hline & & $>10^{5}$ & 24 & 40 \\
\hline \multirow{5}{*}{3} & \multirow{5}{*}{ Treatment Modalities } & $S+E$ & 51 & 85 \\
\hline & & $\mathrm{D} \& \mathrm{C}$ & 02 & 3.33 \\
\hline & & Hysterotomy & 02 & 3.33 \\
\hline & & $\mathrm{S}+\mathrm{E}$ f/b Hysterectomy & 04 & 6.66 \\
\hline & & $\mathrm{S}+\mathrm{E}$ f/b Secondary evacuation & 01 & 1.66 \\
\hline \multirow{3}{*}{4} & \multirow{3}{*}{ Post evacuation Outcome } & Spontaneous Remission & 54 & 90 \\
\hline & & GTN & 05 & 8.33 \\
\hline & & Lost to follow up & 01 & 1.66 \\
\hline \multirow{3}{*}{5} & \multirow{3}{*}{$\begin{array}{l}\text { Antecedent Pregnancies } \\
\text { Among GTN cases }\end{array}$} & Mole & 05 & 100 \\
\hline & & Abortion & 0 & 0 \\
\hline & & Term pregnancy & 0 & 0 \\
\hline
\end{tabular}

\section{Discussion}

Gestational trophoblastic disease (GTD) encompasses a spectrum of pregnancy related trophoblastic abnormalities which include complete and partial moles, placental site trophoblastic tumours, choriocarcinomas, and invasive moles. Molar pregnancies (hydatidiform mole) represent a significant burden of disease on the spectrum of GTDs. The incidence rates of Gestational Trophoblastic Disease vary significantly between different regions of the world.

In this study we found that there were 60 cases of molar pregnancy and 10 cases of neoplasia amongst 39301 pregnancies which gives the incidence 1.52 per 1000 deliveries. Our findings are similar with Jethwani L et $\mathrm{al}^{14}$ who had reported the incidence rate 1.76 per 1000 pregnancies. In another study conducted by Rauf et $\mathrm{al}^{15}$ the incidence of GTD was 1 per 967 pregnancies in a hospital based study. When we compare our results with various studies we found that study conducted in North America, Australia, New Zealand, and Europe reported the incidence of $\mathrm{H}$. Mole ranging from $0.57-1.1$ per 1000 pregnancies, whereas studies in Southeast Asia and Japan have suggested an incidence as high as 2.0 per 1000 pregnancies $^{16}$.

In this study among these 60 cases of GTD, 45 (75\%) cases had complete H. mole, $12(20 \%)$ cases had partial $\mathrm{H}$. mole and $3(5 \%)$ cases had GTN at the time of presentation. During follow up $2(4 \%)$ more patients of complete mole turned into GTN. Our findings are in accordance with the study done by Farhat Khanum et $\mathrm{al}^{17}$ where out of 45 cases of GTD 31(68.8\%) were had complete H. mole , 7(15.5\%) were had partial $\mathrm{H}$. mole and 7 $(15.5 \%)$ were had choriocarcinoma.

In this study most of the patients $(63.3 \%)$ were in age group of 21-30 years which is in accordance with Ramesh Chandran et $\mathrm{al}^{18}$, Vaidya et $\mathrm{al}^{19}$ and Ocheki et $\mathrm{al}^{20}$. However Prazzini et $\mathrm{al}^{21}$ and Sebire et $\mathrm{al}^{22}$ reported complete mole was observed in teenager women and whose age is 36-40 years or above respectively. Occurrence of molar pregnancy represents the release of defective ova.

In this study we found that $\mathrm{H}$. mole was more common in nulliparous women $(38.3 \%)$ followed by para 1 , para 2 , para 3 while the least was women with parity four and above $(6.7 \%)$. Our results are in concordance with Fatima et $\mathrm{al}^{23}$ and Alteiri et al ${ }^{16}$ who also reported $\mathrm{H}$. mole was more common in nulliparous women. 
In this study majority of the patients $83.4 \%$ were geastational age at presentation was $8-20$ weeks while $16.6 \%$ cases have been detected in $<8$ weeks of gestation. No cases were detected after 20 weeks gestation. Our findings are consistent with Jethwani et $\mathrm{al}^{14}$, Madhuri et $\mathrm{al}^{24}$ who all reported most of the cases cases were detected in 8-20 weeks of gestation. In another study Jangbhadur Singh et $\mathrm{al}^{25}$ reported $52 \%$ of cases during 2-5 months gestational age. Detection by ultrasonography played a key factor in diagnosis of GTD.

In this study excessive uterine size was observed among $78.4 \%$ of the cases while $70 \%$ of the cases had beta HCG levels were greater than $100000 \mathrm{mIU} / \mathrm{ml}$ which is in accordance with Madhuri et al ${ }^{24}$ who reorted excessive uterine size than the period of gestation was noted in $77.27 \%$ of cases and beta HCG levels greater than $100000 \mathrm{mIU} / \mathrm{ml}$ in $68.2 \%$ of cases. Similar observation was made by Nousheen Aziz et $\mathrm{al}^{26}$, $57.57 \%$ of cases had uterine size larger than dates and $60.6 \%$ of the cases had beta HCG levels greater than $100000 \mathrm{mIU} / \mathrm{ml}$. Excessive uterine size and high levels of beta HCG indicate majority of cases were in the high risk group, thus requiring higher vigilance and follow up of patients.

In this study the most common clinical presentation was bleeding per vaginum constituting $58.3 \%$ of cases followed by Amenorrhoea 20\%, Pain abdomen $16.7 \%$ while the least common clinical presentation was Incidental US finding after a routine obstetric scan was $5 \%$ of cases. Our results are similar with Madhuri et $\mathrm{al}^{24}$ who reported bleeding per vaginum was the most common presentation in $42.85 \%$ of cases and incidental ultrasound diagnosis in $14.28 \%$ of cases. In another study conducted by Lakra $\mathrm{P}$ et $\mathrm{al}^{27}$ showed bleeding per vaginum $(84.2 \%)$ and pain abdomen $(89.5 \%)$ as the most common presenting symptoms, ultrasound diagnosis in $15.8 \%$ of patients. Nousheen Aziz et $\mathrm{al}^{26}$ reported $81.81 \%$ patients with vaginal bleeding as presenting symptom. Hence, vaginal bleeding associated with pain abdomen is the most common presentation of symptoms and routine obstetric ultrasound helps in early detection of cases.

In this study the primary mode of diagnosis was USG which is in accordance with Santos Ramos ${ }^{28}$, Benson $\mathrm{CB}^{29}$ and Vaidya $\mathrm{A}$ et $\mathrm{al}^{19}$ who reported role of sonograpghy in detecting molar pregnancy. In this study most $(85 \%)$ of the patients were treated by suction evacuation. $6.6 \%$ of the patients treated by suction evacuation followed by hysterectomy. suction evacuation followed by secondary curettage was done in $3.33 \%$ who has excessive bleeding per vagina. Hysterotomy was done as primary treatment in patient who was diagnosed radiologically as partial $\mathrm{H}$ mole with complete placenta previa. The treatment modalities of molar pregnancy were well studied by Hancock B $\mathrm{W}^{30}$, Tidy JA. Soper $\mathrm{JT}^{31}$.

Majority (90\%) of patients had spontaneous remission defined. $8.33 \%$ of the patients who underwent evacuation for $\mathrm{H}$ mole progressed to GTN. One patient lost to follow up (1.6\%). All cases with GTN were found as low risk GTN by modified WHO prognostic scoring system and achieved remission after single agent chemotherapy. Our findings are similar with Ramesh Chandran et $\mathrm{al}^{18}$, in their study $93.6 \%$ of patients were low risk and $6.4 \%$ were high risk and given multidrug chemotherapy to the patients who developed GTN.

\section{Conclusion}

Gestational trophoblastic disease is an important reproductive health problem with $100 \%$ cure rate. Early detection by ultrasound and serum beta HCG values is necessary for treatment of the disease. Routine check up helps to timely management of the GTDs thereby preventing their progression to GTN. They require more vigilance and follow up of patients to prevent relapse and persistence of disease. Prophylactic chemotherapy in such cases is helpful. 


\section{References}

1. Lybol C, Thomas CMG, Bulten J, van Dijck JAAM, Sweep FCGJ, Massuger LFAG. Increase in the incidence of gestational trophoblastic disease in The Netherlands. Gynecol Oncol. 2011;1; 121 (2):334-8.

2. M.J. Seckl, N.J. Sebire, R.A. Fisher, F. Golfier, L. Massuger, C. Sessa, ESMO Guidelines Working Group. Gestational trophoblastic disease: ESMO Clinical Practice Guidelines for diagnosis, treatment and follow-up, Ann. Oncol. 24 (Suppl. 6) (2013) vi39-vi50.

3. Nevin J, Bloch B, Dehaeck K, Soeters R. Gestational trophoblastic disease. Manual of Practical Gynaecological Oncology. London: Chapman and Hall; 1995:130-46.

4. Moore LE, Hernandez E. Hydatidiform Mole [Internet]. Medscape Reference, Web MD LLC. 2014 [cited 2014 Dec 10]. Available from: http://emedicine.medscape.com/article/254 657-overview\#showall

5. Chhabra A, Sinha P. Gestational Trophoblastic Disease - some observation. J ObsGynecol India. 1988;38:590-3.

6. Thapa K, Shrestha M, Sharma S, Pandey S. Trend of complete Hydatidiform mole. J Nepal Med Assoc. 2010;49(1):10-3.

7. Garret LA, Garner EI, Feltmate CM, Goldstein DP, Berkowitz RS. Subsequent pregnancy outcomes in patients with molar pregnancy and persistent gestational trophoblastic neoplasia. J Reprod Med. 2008;53(7):481-6.

8. Kumar N, Saxena Y K, Rathi AK Host and risk factor for GTD: A hospital based analysi from India. Med Sci. Monit 2003;9(10):442-7.

9. Isstd.org>chapter-3-epidemiology; page 58, table 3.2.

10. Goldstein DP, Berkowitz RS. Gestational trophoblastic neoplasms: Clinical principles of disgnosis and treatment. Philadelphia: W B Saunders; 1982:1-301.

11. Bagshawe KD, Dent J, Webb J. Hydatidiform mole in England and Wales 1973-83. Lancet. 1986;328(8508):70-4.

12. Evans AC, Soper JT, Hammond CB. Clinical features of molar pregnancies and gestational trophoblastic tumours. ObstetGynaecol. 2003;87:182-205.

13. Kohorn EI. The new FIGO 2000 staging and risk factor scoring system for gestational trophoblastic disease: description and critical assessment. Int $\mathbf{J}$ gynecol Cancer 2001;11:73-7

14. Jethwani L, Choudhary R, Bhati I, Choudhary V Clinico-Epidemiological Profile of Molar Pregnancies at A Tertiary Care Centre of India: A Prospective Observational Study. International journal of Scientific Research 2007;6(7):45-8

15. Rauf B Hassan Rauf B, Hassan L, Ahmed S. Management of gestational trophoblastic tumors: a five-year clinical experience. J Coll Physicians Surg Pak 2004; 14:540-4

16. Altieri A, Franceschi S, Ferlay J, Smith J, La Vecchia C. Epidemiology and an etiology of gestational trophoblastic disease. Lancet Oncol 2003;4:670

17. Farhat Khanum, Sadia Shamsher. Gestational trophoblastic disease: experience at a tertiary care hospital of Peshawar. Jpmi 2010;24(02):127-32

18. Ramesh Chandran Jyoti Ramesh Chandran, Uma Devi N, Sumangala Devi, Sajala Vimal Raj. Epidemiology of Complete Hydatidiform Mole at a Tertiary Hospital and Analysis of Cases over Last 5 Year Period. Indian Journal of Maternal and Child Health 2011;13(4):1-8

19. Vaidya A. Molar Pregnancy - Clinical Trends at Maternity Hospital. Postgraduate medical journal of national academy of medical science 2008;8(1):1-6. 
20. Ochecki Amaka N Ocheke, Jonah Musa, Alexander O Uamai. Hydatidiform mole in Jos, Nigeria. Niger Med J 2011;52(4):2236.

21. Parazzini F, LaVecchia C, Mangili G. Dietary factors and risk of trophoblastic disease. Am J Obstet Gynecol 1988;158:93-9.

22. Sebire NJ, Foskett M, Short D, Savage P, Stewart W, Thomson M et al. Shortened duration of human chorionic gonadotrophin surveillance following complete or partial hydatidiform mole: evidence for revised protocol of a UK regional trophoblastic disease unit. BJOG 2007; 114(6):760-2

23. Fatima M, Kasi PM, Baloch SN, Kassi M, Marri SM, Kassi M Incidence, Management and Outcome of molar pregnancies at tertiary care hospital in Quetta, Pakistan. ISRN ObsGynecol 2011; 925316

24. Madhuri Chinthalal, D Srividya Sarma Gestational trophoblastic disease: study on incidence and management at a tertiary centre. Indian Journal of Basic and Applied Medical Research; December 2017;7(1):317-24

25. Jangbhadur Singh, Shaveta Sharma, KirpalKour, Shazia Bashir. Prevalance of molar pregnancy (a three-year retrospective study) in a tertiary care hospital. Annals of Applied Bio-Sciences 2016;3(1):1-4

26. Nousheen Aziz, Sajida Yousfani, Irfanullah Soomro, Firdaus Mumtaz, Gestational Trophoblastic Disease, www.ayubmed.edu.pk/JAMC/24-1

27. Lakra P, Vijayata Sangwan, Sunita Siwach, Richa Kansal, Rajiv Mahendru, Anjali Sharma. Outcome of gestational trophoblastic disease in a rural tertiary centre of Haryana, India. Int J Reprod Contracept Obstet Gynaecol 2017; $6(1): 271-5$.
28. Santos-Ramos R, Forney JP, Schwarz BE. Sonographic findings and clinical correlations in molar pregnancy. Obstet Gynecol 1980; 56:186-92

29. Benson CB, Genest DR, Bernstein MR, Soto-Wright V, Goldstein DP, Berkowitz RS. Sonographic appearance of first trimester complete hydatidiform moles. Ultrasound ObstetGynecol2000;16:188-91

30. Hancock BW, Tidy JA. Current management of molar pregnancy. J Reprod Med 2002;47:347-54

31. Soper JT. Surgical therapy for gestational trophoblastic disease. J Reprod Med 1994; 39:168-74. 